\title{
Material application methodologies for winter road maintenance: a renewed perspective
}

\author{
Sen Du, Michelle Akin, Dave Bergner, Gang Xu, and Xianming Shi
}

\begin{abstract}
Winter roadway operations, commonly known as snow and ice control operations, are one of the most critical functions of state, provincial, and local transportation agencies in cold regions. These operations aim to provide safety and mobility through the timely and effective application of materials and mechanical removal. The most common materials used are salt (sodium chloride, solid or liquid brine), magnesium chloride-based, calcium chloride-based deicers, agro-based additives and blends, and abrasives. In practice, the specific choice and application method and rate of these materials are dependent on pavement temperature, precipitation type, level of service goals, budget, and environmental sustainability considerations. Best practices of material application are designed to apply the right type and amount of materials in the right place at the right time. This review presents a literature review and agency interviews that were conducted to gather information about the use of materials, including types of materials, application strategies, application rates, and application equipment.
\end{abstract}

Key words: winter road maintenance, review, material, strategy, application rate, equipment.

Résumé : Les opérations hivernales sur les routes, communément appelées opérations de déneigement et de déglaçage, sont l'une des fonctions les plus critiques des organismes de transport d'État, provinciaux et locaux dans les régions froides. Ces opérations visent à assurer la sécurité et la mobilité par la rapidité et l'efficacité de l'épandage de matériaux et du déblaiement de la neige. Les matériaux les plus couramment utilisés sont le sel (chlorure de sodium, solide et saumure), et les matériaux déglaçants à base de chlorure de magnésium et de chlorure de calcium, les additifs et mélanges agro-industriels et les abrasifs. En pratique, le choix et la méthode d'épandage spécifiques de ces matériaux dépendent de la température, du type de précipitation, des objectifs de niveau de service, du budget et de la durabilité environnementale. Les meilleures pratiques d'épandage des matériaux sont conçues afin d'épandre le bon type et la bonne quantité de matériau au bon endroit au bon moment. Cet exam présente une revue de la littérature et des entrevues menées par des organismes pour recueillir de l'information sur l'utilisation des matériaux, y compris les types de matériaux, ainsi que les stratégies, les taux et l'équipement d'épandage. [Traduit par la Rédaction]

Mots-clés : entretien hivernal des routes, revue, matériau, stratégie, taux d'épandage, équipement.

\section{Introduction}

Approximately $70 \%$ of the US roads are located in snowy regions, with nearly $70 \%$ of the US population living in these regions (FHWA 2013). As such, there is a great demand for effective strategies and tactics for winter road maintenance (WRM). The WRM is one of the most critical responsibilities of state departments of transportation (DOTs) in cold climates. Such maintenance operations often involve various strategies to improve the level of service (LOS) on roadways, such as plowing, deicing, anti-icing, sanding, and snow fencing. Generally, a combination of these strategies is adopted by transportation agencies to ensure the safety, mobility, resiliency, and productivity of roadways during winter weather. Among these strategies, the application of materials (chemicals or abrasives) plays a very important role. Best practices of material application aim to apply the right type and amount of materials in the right place at the right time, thus achieving an appropriate LOS under the given road weather scenarios with reduced cost and minimized negative impacts.

Common chemical materials used for WRM operations include freezing point depressants with chloride (e.g., sodium chloride
$(\mathrm{NaCl})$, magnesium chloride $\left(\mathrm{MgCl}_{2)}\right.$, and calcium chloride $\left.\left(\mathrm{CaCl}_{2}\right)\right)$, as well as non-chloride products such as acetates (e.g., calcium magnesium acetate (CMA) and potassium acetate (KAc)) and agro-based byproducts (e.g., proprietary products from beet, corn, distilleries, or cheese making). Application strategies include anti-icing (treating roads before snow bonding to pavement) and deicing (during and post-snowfall to facilitate mechanical removal of snow and ice from pavement). Anti-icing is usually performed with liquid products, but pre-wet salt can also be used. Deicing is the most common strategy and is usually required during most storms, even if anti-icing has been performed. Dry and pre-wet salts are the most common materials used for deicing, but direct liquid application can also be used effectively, especially for storms with warmer temperatures, light snowfall, and on routes with shorter cycle times (Peterson et al. 2010). Pre-wetting uses liquid chemical to pre-wet solid deicers or abrasives at the spinner just before application onto the road.

As winter roadway operations have significantly improved over the past several decades, there is a need to synthesize the renewed knowledge and localized agency experiences, especially regarding the increasing awareness and concerns of the negative

Received 20 July 2019. Accepted 14 May 2020.

S. Du, M. Akin, G. Xu, and X. Shi. Department of Civil \& Environmental Engineering, Washington State University, Pullman, WA 99164, USA.

D. Bergner. Monte Vista Associates, LLC, Mesa, AZ 85205, USA.

Corresponding author: Xianming Shi (email: xianming.shi@wsu.edu).

(c) 2021 The Author(s). Permission for reuse (free in most cases) can be obtained from copyright.com. 
Fig. 1. Map of interviewee locations. Figure was created using Microsoft $₫$ Excel Version 16.41 and assembled from the following data source: https://commons.wikimedia.org/wiki/File:Map_of_US_state_cannabis_laws.svg. Base map from Lokal_Profil (2020). [Colour online.]

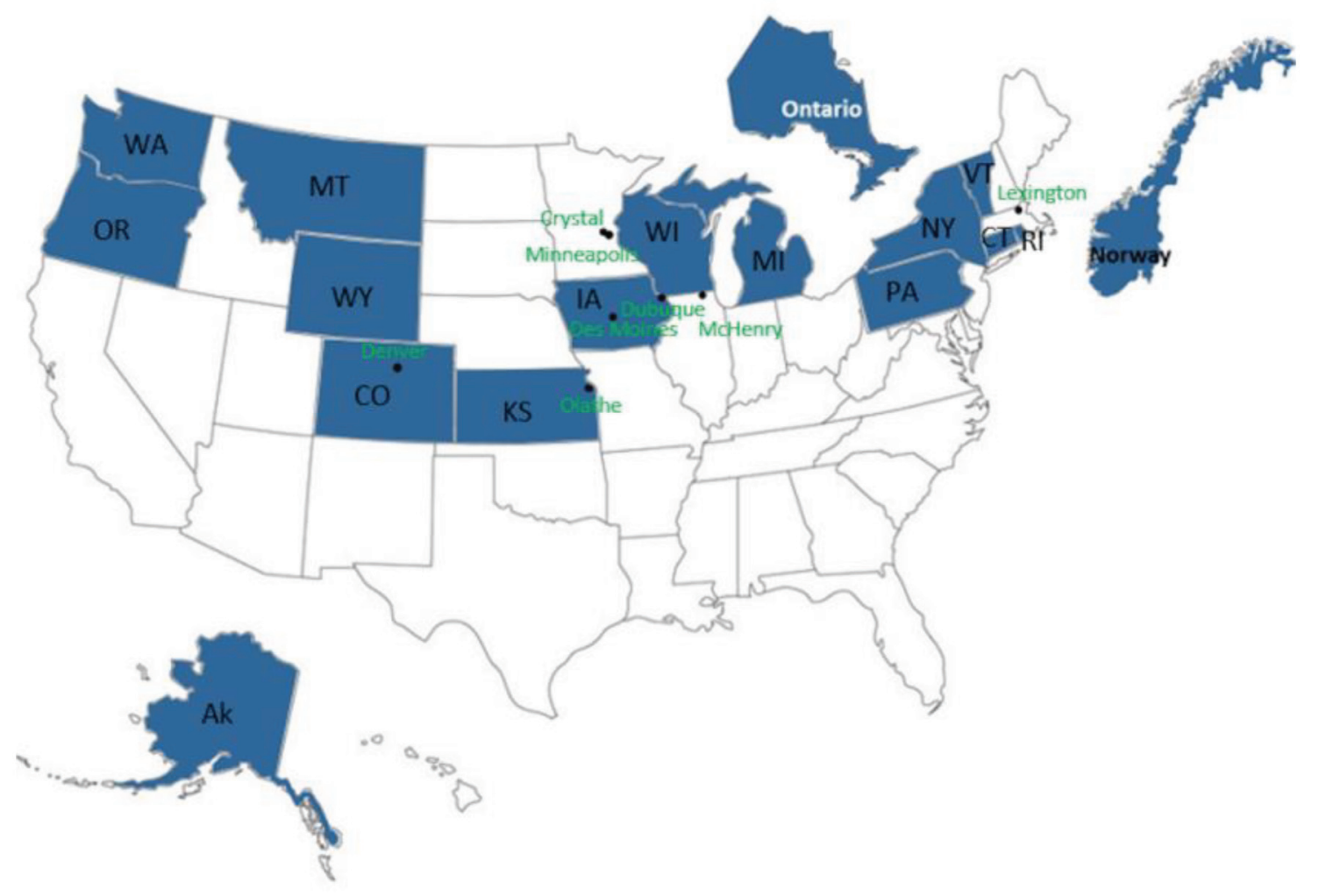

impacts of winter maintenance materials (e.g., chloride loading). In particular, many regions have transitioned to the wider use of chemicals instead of abrasives, and used anti-icing to reduce overall chemical usage and provide greater levels of service (Staples et al. 2004; Cui and Shi 2015). This necessitates a review of the methodologies and application rates of solid salt, salt brine, and other products used for snow and ice control operations.

In this context, this review begins by considering the factors that influence the selection of materials. These factors, many of which are inter-related, have different priorities in the decisionmaking of choice or timing of material application. Then, a summary of the commonly used materials in WRM is presented, focusing on their effective temperatures and application in appropriate methodologies. The application rate of the materials, which is the most important factor that needs to be considered in the WRM practice, is also synthesized from practices derived from the updated guidelines and experiences. Finally, the state of knowledge relevant to the application equipment is reviewed, given that the technologies in WRM have developed significantly in recent years.

\section{Methods}

To develop a comprehensive review of WRM material applications, a method that included a literature search and practitioner survey was used. For the literature search, significant efforts have been made over the last several decades and have resulted in a wealth of information related to winter maintenance materials and application methodologies. The databases used for this research were mainly Google Scholar and ScienceDirect for peerreviewed journal papers and conference proceedings. Technical reports from agencies were searched directly through Google, since most of them were not included in the mentioned databases. Some information on the local agency websites was also cited according to their relevance to the review topic. The keywords for these searches included winter maintenance, deicer, salt, sand, deicing, anti-icing, pre-wetting, snow removal, snow and ice control, environmental impact, and equipment. Through this approach, approximately 100 relevant publications were found and included in this review.

Additionally, many agencies (DOTs and city/county road departments) have developed in-house material application rate guidelines based on their local and practical experiences. Therefore, a survey was conducted with winter maintenance personnel over phone and in person to gather information about the material application methodologies across various transportation agencies. A total of 26 completed responses were collected during the survey process, including 16 winter maintenance personnel from state DOTs, eight responses from city/county governments, one from Canadian province (Ontario), and one from a European country (Norway). A map showing the distribution of interviewees is shown in Fig. 1. The survey questions were developed based on knowledge learned from the literature review and designed to gather information on the evolution of material applications over time, methods observed most useful, tailored/custom application operations, and factors influencing winter operations. It should be noted that since jurisdictions have varied weather and geographical characteristics, the survey results are only qualitative. If the statistical resilience or potential biases needed to be tested, the number of survey respondents have to be added. In this review, the survey responses were expected to provide experience and insights from winter maintenance practitioner community.

\section{Factors that affect material application}

The key to WRM material application is to apply the right amount of the right material, in the right place, and at the right time (TAC 2013). Many inter-related factors influence the choice 
or timing of material application, including LOS, climatic conditions and predominant weather patterns, traffic, material cost, material availability, environmental concerns, corrosion to fleet and infrastructure, etc.

Providing a high LOS to the traveling public is a key objective for WRM operations (Veneziano et al. 2014). LOS in this context is a set of operational guidelines and procedures that establish the timing, type, and frequency of treatment (Xu et al. 2017). Clear specification of LOS requirements is an essential part of any salt management plan (SMP), as such requirements balance the need to maintain safe conditions for roadways against the economic, infrastructure, and environmental effects of salting. The survey results indicate that LOS has the highest priority when agencies manage their material usage, application methodologies, and application equipment. As a key index of LOS, the bare pavement regain time (BPRT) is significantly affected by the salt application rates (Trenouth et al. 2015). Generally, application rates tend to increase as LOS increases. On the other hand, low LOS goals may preclude the use of anti-icing (City of Brockville, 2018).

The climatology of a particular area defines the historical average of the type and amount of precipitation that can be expected during a typical winter (Blackburn et al. 2004). More importantly, for WRM operations, the distribution of winter precipitation types in an area should be considered. Weather can be characterized by describing the meteorological elements associated with storm events (Blackburn et al. 2004), such as precipitation type and amount, visibility, wind speed and direction, temperature, and relative humidity. For example, maintenance operations used in the early stage of a storm typically need to be modified when applied during the course of a storm. Material application in a light snowfall interspersed with heavy snowfall should differ from that in a single snowfall (Ketcham et al. 1996). Wind is another main weather pattern that influences the application of materials. Experience has shown that it is important to adjust the sprayer closer to the pavement to achieve a desirable material application during windy conditions (Ketcham et al. 1996). If wind causes blowing and drifting snow to cross the road, anti-icing should not be performed; otherwise, the blowing snow will stick to the road instead of blowing across.

Understanding road weather is important for successful winter material applications. Weather forecasting services can provide forecasts specific to road-based information (TAC 2013). Precipitation can take many forms during winter storms, such as snow, frost, freezing rain, black ice, and sleet (MnDOT 2010). Black ice is a thin and clear layer of ice that forms on a non-frozen pavement surface when the air temperature is slightly below freezing (approximately $-1{ }^{\circ} \mathrm{C}$ ). Freezing rain causes a hard and generally thick layer of ice on pavement through liquid precipitation on the pavement at temperatures below freezing (Blackburn \& Associates 2014). It is generally accepted that weather plays an important role in controlling variability in WRM (Matthews et al. 2017). Using the best available weather data is critical for the maintenance authority to choose materials effective for local road temperatures, determine the best application methodology, and plan for appropriate bulk materials for the anticipated season (Dindorf and Fortin 2014; Shi 2020).

Traffic considerations include those related to operational difficulty and timing, as well as treatment effectiveness and longevity (Blackburn et al. 2004). For anti-icing, the traffic rate and volume may affect the longevity of the chemical product on the pavement. It has been reported that anti-icing operation with liquid products can be successful in both high-volume rush-hour traffic and low-volume middle-of-night traffic (Ketcham et al. 1996). However, when solid chemicals and abrasives are applied before precipitation, traffic can cause materials to be blown, scattered, and transported from the pavement surface (Blackburn et al. 2004). Conceptually, traffic can be beneficial for deicing operations. Specifically, traffic-related agitation can facilitate the melting
Fig. 2. Approximate price (unit in USD) of solid materials for snow and ice control (actual price depends on local availability and transportation costs). [Colour online.]

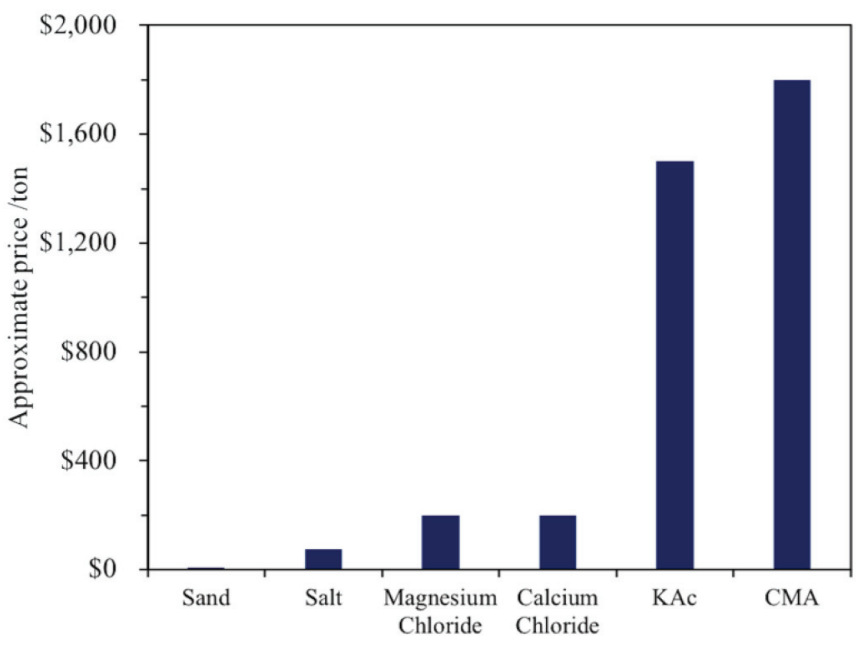

of ice by the chemical product and subsequent penetration and undercutting of the ice layer by the liquid, helping to break the bond of ice (or compacted snow) to the pavement.

Cycle time is primarily a function of the number of personnel and the amount of equipment available to treat the assigned roadway system (Blackburn et al. 2004). Longer cycle times allow more precipitation to accumulate on the roadway between treatments; as such, they would require more chemicals to be applied to achieve equivalent effectiveness. In particular, compared with salt brine alone, agro-based products blended with salt brine were found to stay on the road surface longer, thereby improving the ability to prolong the performance of deicers and allow a longer cycle time (Muthumani et al. 2017). In a recent study, the salt was found to melt snow faster on asphalt concrete pavement than on portland cement concrete (PCC) pavement, which requires a shorter cycle time for the salt to achieve the same melting performance (Hossain et al. 2016). However, too short a cycle time may cause materials to be plowed from the road before deicer penetration and undercutting are able to sufficiently weaken the snow/ pavement bond.

The cost and availability of materials often play an important role in the selection of material application methodologies for WRM operations. Figures 2 and 3 illustrate the up-to-date approximate average price (unit in USD) of commonly used snow and ice control materials, using data from the literature search and personal communications. These are only one aspect of the direct cost (purchase price) of materials, which is highly dependent on local availability and transportation costs. Other considerations regarding material type include operational costs (labor and equipment) and application rates. For example, sand has the lowest purchase price, but factoring in the higher application rate means more material needs to be purchased and more labor and equipment hours are needed to apply it (and clean it up in the spring) - all of which increase the total direct cost of sand. A Washington State DOT study demonstrated with several case studies that traditional deicing operations using sand/salt mixture costs 3 to 12 times more than an anti-icing operation using liquid $\mathrm{MgCl}_{2}$ and provides worse road conditions (Dye et al.1996). Moreover, the overall cost of applying materials on the road should be considered, which includes the direct costs of material, labor, and equipment, and indirect costs associated with damage to the environment, vehicles, and infrastructure caused by the applied material. For instance, the overall cost of salt was estimated to be up to $1026 \mathrm{USD} /$ ton, while the direct cost for salt 
Fig. 3. Approximate price (unit in USD) of liquid material for snow and ice control (actual price depends on local availability and transportation costs). [Colour online.]

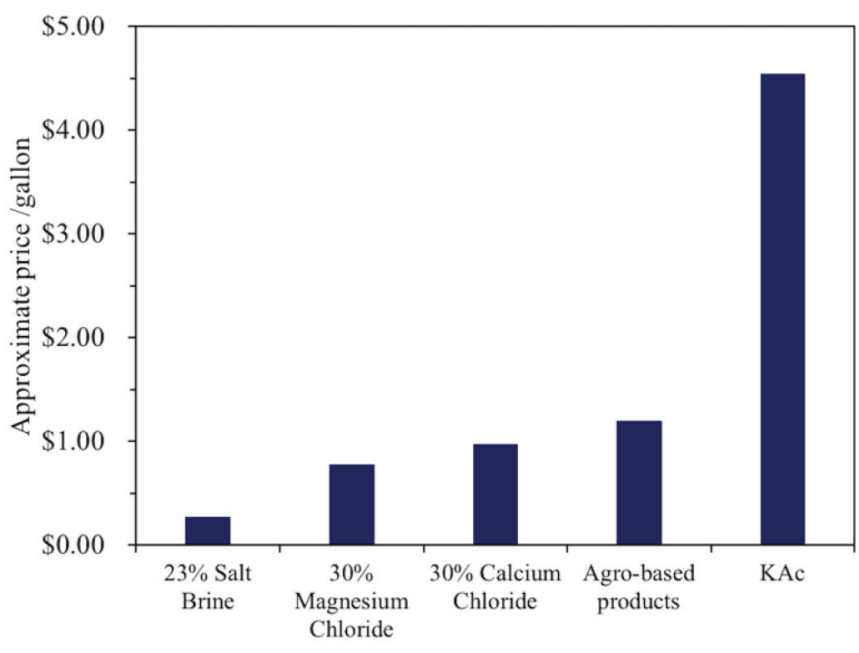

was only 73 USD/ton in the Twin Cities Metro Area in Minnesota (Dindorf and Fortin 2014). In practice, reducing the cost is the first goal that agencies consider achieving when conducting WRM operations, according to the survey results.

While providing many benefits to winter traffic mobility, once the snow and ice control materials leave the roadway, they can negatively impact the natural environment, particularly with respect to surface water, groundwater, soil, vegetation, aquatic biota, and wildlife (Fischel 2001; Nazari et al. 2021). Abrasives impact the environment mainly through air pollution caused by PM-10 particles and water pollution by increased turbidity and reduced oxygen concentration in water bodies (Staples et al. 2004). In contrast, chloride salts impart different impacts to the environment, through rising concentrations of chlorides and the associated cations $\left(\mathrm{Na}^{+}, \mathrm{Mg}^{2+}, \mathrm{Ca}^{2+}\right)$ in water bodies and soils, mobilization of heavy metals, and impacting roadside vegetation and wildlife (Fay and Shi 2012). It is believed that 10\%-60\% of the applied road salts enter shallow subsurface waters (Environment Canada 2002). The gradual increases in sodium $\left(\mathrm{Na}^{+}\right)$and chloride $\left(\mathrm{Cl}^{-}\right)$concentrations by $130 \%$ and $243 \%$, respectively, measured in a New York river over a 50-year study period, are attributed to deicing salts (Goodwin 2003). Higher $\mathrm{Na}^{+}$and $\mathrm{Cl}^{-}$concentrations in lakes have been observed in winter and spring, while lower concentrations have been observed in summer and fall (Novotny et al. 2008). This can be attributed to road salt use during winter and flushing by rainfall. For glycols, acetates, formates, or agrobased deicers, a high organic content may lead to temporary anaerobic soil conditions and localized depletion of dissolved oxygen in aquatic ecosystems (Fay et al. 2014). An investigation of common airport runway deicers showed that formates feature low biological oxygen demand (BOD) and chemical oxygen demand (COD) but long biodegradation time, while acetates and glycerol have high BOD and COD but short degradation times (Schweigert 2016).

The risk of corrosion to maintenance vehicles and infrastructure by snow and ice control materials should also be a factor that influences the choice of material type and its appropriate application. The detrimental effects of chemicals on concrete and reinforcing steel within concrete are generally more serious than those on exposed equipment. Corrosion inhibitors are often added to anti-icing or deicing materials to reduce their corrosivity to bare metals (Fischel 2001), and they may also slow down the corrosion initiation of embedded rebars and dowel bars in concrete (Shi et al. 2010). Generally, road salt ( $\mathrm{NaCl}$, without any inhibitor) is more corrosive than other chemical products if tested under continuous immersion conditions. However, under conditions of exposure to wet/dry cycles, $\mathrm{MgCl}_{2}$ can be more corrosive to steel than $\mathrm{NaCl}$ (Xi and Oisgard 2000; Shi et al. 2009a). The corrosion risk of various deicers is also a function of the metal type and washing practices (Nazari et al. 2017).

\section{Materials used for WRM operations}

Chemical deicers and abrasives have been used for snow and ice control in the United States since the 1930s (Fischel 2001). Presently, the most common freezing point depressants (FPDs) used for roadway winter operations are $\mathrm{NaCl}, \mathrm{MgCl}_{2}$, and $\mathrm{CaCl}_{2}$, and, to a much lesser extent, CMA and KAc. Chloride salts are the most readily available and widely used salts in either solid or liquid forms (Shi et al. 2009b). While these materials enable many roads to remain open during winter storms, numerous studies have indicated that they can have harmful effects on motor vehicles (Johnson 2000; Li et al. 2013; Sajid et al. 2020), transportation infrastructure (Sutter et al. 2008; Xie et al. 2016, 2019; Qiao et al. 2021), and the environment (Fay and Shi 2012; Zhang et al. 2013; Nazari et al. 2021). However, these snow and ice control materials are still widely used in winter road maintenance because of their beneficial impact of increasing the safety of winter driving. Shi et al. (2009b) reported that most winter maintenance agencies still relied on chlorides and abrasives for snow and ice control on highways.

A frequent finding in surveys of winter maintenance personnel is that many states have transitioned to using more chemicals than abrasives, and have also indicated a related shift from solid materials to more liquids (Conger 2005). However, sand is still used by many states, particularly during extremely cold temperatures and low-volume, low-LOS routes. According to the Clear Roads annual winter data survey, even during the 2016-17 winter season, very few states applied no amount of abrasives. Sodium chloride $(\mathrm{NaCl})$ is the most commonly used material for WRM because it is traditionally abundant and inexpensive (Fischel 2001). As expected, the survey respondents from the snowy regions report that salt, in solid or liquid form, is the most used chemical during winter events. Table $S 1^{1}$ in the Supplementary data lists the commonly used materials for WRM operations and their corresponding traffic conditions and treatment types from relevant references.

The performance of anti-icing and deicing materials at low temperatures is commonly determined by the eutectic temperature (determined from laboratory tests, such as ASTM D1177) and the lowest effective temperature (typically determined from field observations and anecdotal evidence of performance). The term "eutectic temperature" is defined as the lowest freezing point and has a corresponding eutectic concentration (Keep and Parker 2000). This can be seen clearly through a phase diagram (such as the $\mathrm{NaCl}$-water system), as shown in Fig. 4. The freezing point of the solution decreased as the concentration increased until the eutectic point was reached. For $\mathrm{NaCl}$, this occurs at a temperature of $-21^{\circ} \mathrm{C}$ and a concentration of $23.3 \%$ (Nixon and Williams 2001). A chemical with a low eutectic temperature is expected to have high miscibility or solubility in water. In anti-icing and deicing practices, the larger the difference between the eutectic temperature and ambient temperature, the faster the snow and ice melt (Fischel 2001). Therefore, it is ideal for the chemicals to have a eutectic temperature well below the expected ambient temperature, resulting in a rapid dissolution of chemicals and a low freezing point of the brine solution.

\footnotetext{
${ }^{1}$ Supplementary data are available with the article at https://doi.org/10.1139/cjce-2019-0465.
} 
Fig. 4. Phase diagram for the salt-water system.

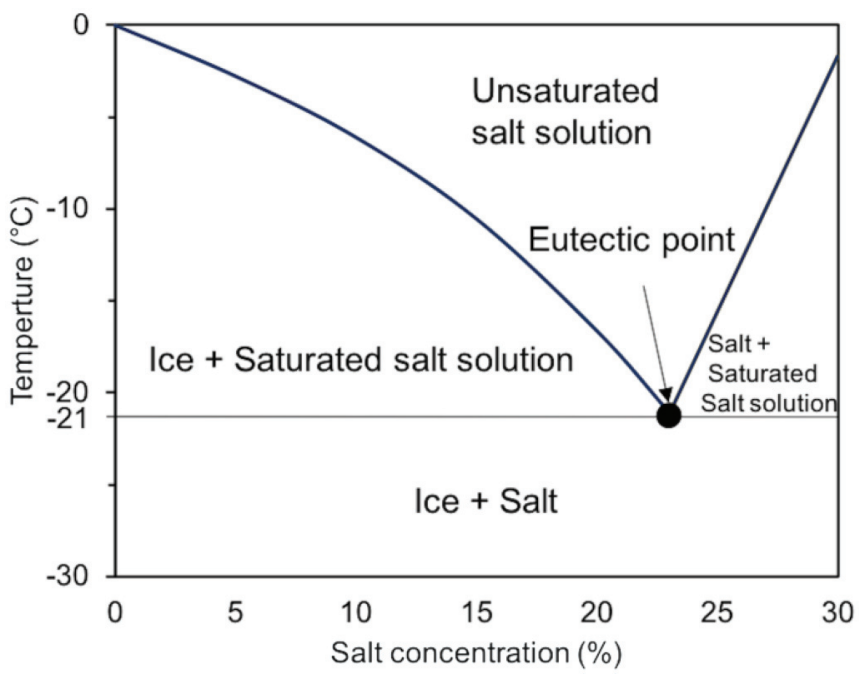

However, most chemicals cease to be effective before the eutectic temperature is reached. For instance, $\mathrm{NaCl}$ is rarely used when the ambient temperature is below $-9{ }^{\circ} \mathrm{C}$, even though its eutectic temperature is $-21^{\circ} \mathrm{C}$ (Nixon and Williams 2001). Thus, it is necessary to introduce the effective temperature, which is used to describe the lowest temperature for chemicals in practical use (Fischel 2001). Nixon and Williams (2001) suggested that the lowest effective temperature is the temperature on the phase diagram corresponding to a solution concentration that is half of the eutectic concentration (11.65\% and $-8{ }^{\circ} \mathrm{C}$ for $\left.\mathrm{NaCl}\right)$. The lowest practical pavement temperatures for common chloride-and acetate-based deicers, as reported by many sources, are listed in Table 1. Generally, it is expected that anti-icing and deicing chemicals with low eutectic and effective temperatures will work better at low temperatures. Survey results show that some agencies stated that they need chemicals that are more effective at low temperatures and less corrosive.

\section{Material application methodologies}

Various material application methodologies, including antiicing, deicing, sanding (or use of abrasives), and pre-wetting, are available for applying snow and ice control materials onto roadways. Depending on climatic conditions, site-specific factors, local rules of practice, resources available, and LOS goals, an agency's decision will be one of these methodologies, or a combination (Levelton Consultants 2007). There are two distinct material application methodologies that make use of chemical freezing-point depressants: anti-icing and deicing. They differ in their fundamental objectives, where anti-icing is a preemptive strategy of applying chemicals to prevent snow and ice from bonding to the pavement, and deicing is a reactive strategy needed to break bonds between snow and ice and pavement. Some agencies still use abrasives as temporary traction improvement when snow/ ice is bonded strongly to the pavement, either during very low temperatures or until warmer temperatures permit effective plowing. Pre-wetting solid deicers with liquid chemicals can be used for either anti-icing or deicing strategies. Pre-wetting abrasives help reduce their bounce-and-scatter and improve the longevity of the abrasives.

\subsection{Anti-icing}

Many field tests and documented agency experiences have proven anti-icing as a successful tactic for WRM. Anti-icing practice is a preventive operation that applies a chemical freezing-point depressant onto the pavement at the start of a winter storm, or even prior to the beginning of precipitation, to inhibit the development of a bond between snow or ice and pavement surface (Ketcham et al. 1996). Furthermore, moderate and periodic reapplication of chemicals during storms can continue this effect. Once applied, chemicals remain on the pavement to work through the next storm event until they are diluted by precipitation. As a result, anti-icing leads to improved LOS, reduced need for chemicals, cost savings, and benefits in safety and mobility relative to deicing and sanding (Ketcham et al. 1996; Conger 2005; CTC \& Associates LLC 2009). A recent study indicated a $10 \%-40 \%$ improvement in the friction level by anti-icing treatments (Hosseini et al. 2014). It has also been proven that antiicing operation can be very effective in preventing bridge deck and pavement frost (Wisconsin TIC 2005). In recent years, antiicing practices have been widely adopted by state agencies across the US, using a variety of materials (Rubin et al. 2010; Rainwater et al. 2021).

Anti-icing is commonly performed with liquid materials, although it is possible to use dry or pre-wet solid granular materials (Nixon and Williams 2001; TAC 2013). This is because liquids can attach to dry pavement better, while solid materials are dispersed by traffic action (Kahl 2002). In practice, liquid anti-icing operations should be conducted when the temperature is above $-9{ }^{\circ} \mathrm{C}$ (Peterson et al. 2010; Wisconsin TIC 2005). However, it was found that anti-icing materials can improve the ability of a plow to remove snow from the pavement surface, even at temperatures lower than $-10{ }^{\circ} \mathrm{C}$ (Cuelho et al. 2010). Reliable and accurate information on weather and pavement conditions, such as that provided by road weather information systems (RWIS), and weather forecasts are key to effective anti-icing operations (Mitchell et al. 2003; Venner Consulting and Brinckerhoff 2004). One report suggested that anti-icing on a regular basis (e.g., twice per week) is a recent trend (Mitchell et al. 2006).

\subsection{Deicing}

In contrast to anti-icing operation, a common procedure of deicing practice is to wait until two centimeters or more of snow has accumulated on the pavement before beginning to plow and treat roadways with chemicals or abrasives (Ketcham et al. 1996). This traditional snow and ice control practice frequently leads to a compacted snow layer (pack) that is tightly bonded to the pavement surface. To destroy or weaken this bond, a large quantity of chemical products is usually required to work through the pack to reach the snow-pavement interface. When a thin layer of chemical solution reaches the interface between ice and pavement, the ice-pavement bond is eventually weakened (Cuelho et al. 2010). Once the bond is weakened or broken, the snow and ice layers can be easily removed by mechanical means such as snowplows.

Because the deicing operation is a reactive (versus pro-active) strategy to manage the changing condition on pavements, it often provides less safety at a higher cost than anti-icing operation. One concern about deicing operations is the increased potential for accidents due to slippery pavement surface conditions prior to and during maintenance activities (Cuelho et al. 2010). Another concern is the large quantity of materials and labor hours required to maintain a desirable LOS (O'Keefe and Shi 2005). However, deicing is still an appropriate technique for roadways with a lower priority service level, or in situations where weather forecasts are inaccurate or anti-icing operations are precluded (Ketcham et al. 1996). Deicing is critical for maintaining safety and mobility during storms of long duration or extended periods of cold drifting conditions. Moreover, deicing operation with solid chemicals is the most effective method for thick snow accumulation (Cuelho et al. 2010). In addition, deicing allows for higher traffic speed and volume, reduces the need for abrasives, 
Table 1. Lowest practical or effective working temperatures of chloride- and acetate-based materials.

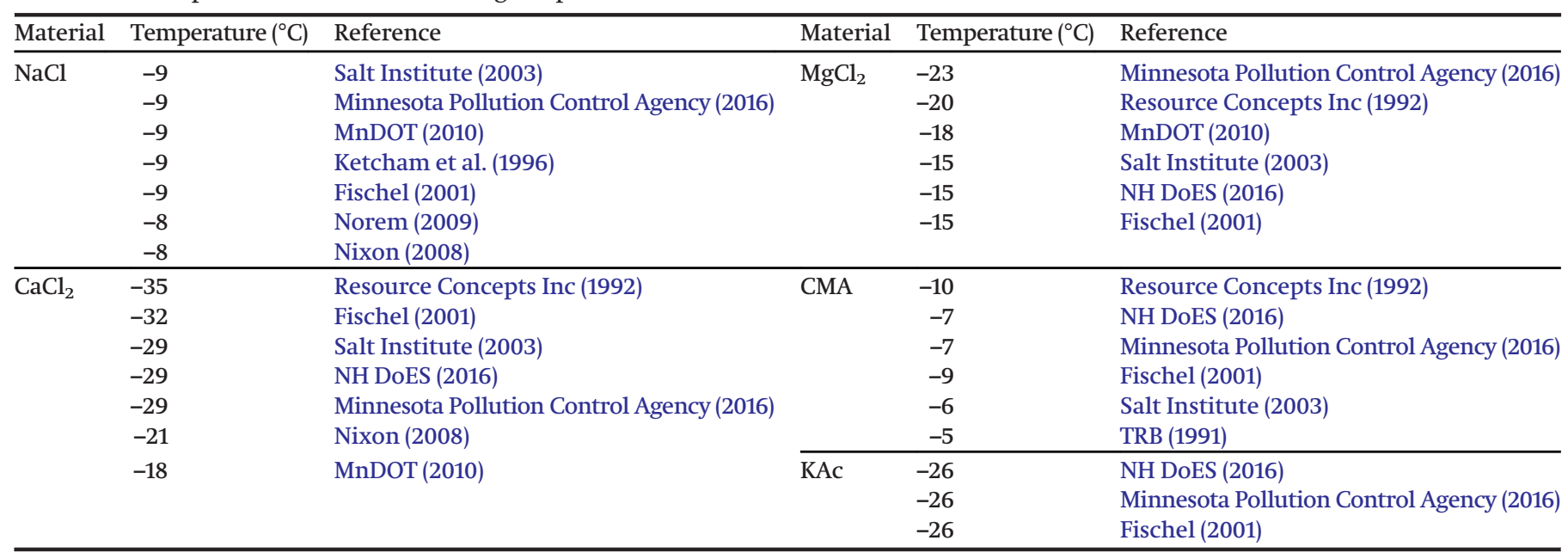

and saves on fuel consumption, compared with snowplowing alone (Fischel 2001).

In recent years, agencies have explored the use of liquid materials for deicing, called direct liquid application (DLA), in which only liquid materials are used before, during, and after a storm (Fortin Consulting 2017). When employed in conditions with pavement temperatures above $-7{ }^{\circ} \mathrm{C}$, DLA has the benefits of reduced application rates, reduced loss of materials, faster post-storm cleanup, quicker effect, and lower corrosion effects (Peterson et al. 2010) because liquids are fully retained on the pavement and begin melting immediately (TAC 2013). While DLA is especially effective at removing frost or thin layers of snow or ice, it can easily cause a slick layer of melting that may refreeze on the surface of compacted snow and ice if applied incorrectly (Fortin Consulting 2017).

\subsection{Pre-wetting}

\subsubsection{Pre-wetting salt}

Pre-wetting salt with a liquid chemical immediately before it is spread on pavement aims to improve performance by accelerating the process of solid chemical particles entering the solution and keeping material on the pavement by reducing the loss or waste from bouncing, blowing, sliding, and traffic action (TAC 2013; Burtwell 2004). For example, one field test showed that $80 \%$ of the pre-wetted salt remained on a road surface after 100 vehicles traveling at $61 \mathrm{~km} / \mathrm{h}$, while only 15\% remained for dry salt (Evans 2008). Moreover, it has been reported that pre-wetted rock salts can melt precipitation immediately (Kahl 2002). Increased snow and ice melting capacity may be observed due to the combination of solid and liquid chemicals being used (Alger and Haase 2006). One laboratory study confirmed that pre-wetting 1 ton of solid salt with 8 to 16 gallons of liquid products effectively improved the amount and speed of ice-melting (Zhang et al. 2020). As a result, prewetting may provide significant potential for reduction in chemical use, with typical savings of $25 \%-30 \%$ commonly reported (Burtwell 2004; Maine DOT 2003). In practice, it has been found that 10 to 12 gallons of $23 \mathrm{wt}$.\% of $\mathrm{NaCl}$ solution will be sufficient for 1 ton of dry chemicals of coarse gradation (Blackburn et al. 2004). Field studies in Ontario of pre-wetted salt with liquid $\mathrm{CaCl}_{2}$ and $\mathrm{MgCl}_{2}$, as expected, outperformed dry salt in most test cases, with $\mathrm{CaCl}_{2}$ outperforming $\mathrm{MgCl}_{2}$ (Fu et al. 2006). Survey results indicate that the most commonly used chemical for pre-wetting is salt brine. In addition, at least half of the interviewed agencies mentioned using alternative liquids, primarily $\mathrm{MgCl}_{2}, \mathrm{CaCl}_{2}$, and agro-based products, during colder temperatures. Several agencies are transitioning to using $100 \%$ pre-wetted solids and phasing out the use of dry solids.
Typically, a pre-wetting liquid is applied to the spinner. According to the survey results, some agencies treat the solids at the stockpile or when loading trucks. Pretreating salt stockpiles or truck loads with liquids is an alternative to onboard pre-wetting. Laboratory testing of various pretreat chemicals and rates found no significant benefit either to the ice melting capacity (Alger and Haase 2006) or to the friction coefficient of the treated pavement surface (Zhang et al. 2020), but the benefits were notable in reducing the snow-pavement bond strength (Zhang et al. 2020). Field testing of dry salt versus two pre-wetted salts in Ontario over two winter seasons demonstrated that one type of prewetted salt can be applied at application rates of $15 \%$ lower than dry salt, whereas application rates of another type of pre-wetted salt can be 30\% less than dry salt (Radaelli and Dizaji 2017).

\subsubsection{Pre-wetting sand}

Pre-wetting sand helps keep abrasives on the road surface, attributed to the liquid coating on the sand melting just enough of the snow pack to allow the abrasives to embed into the surface (Nixon 2001). The embedded sand in the snow pack provides a roughed sand-paper-like surface. For pre-wetted abrasives, the reduction in the amount applied can be as high as 50\% compared with normal abrasives at low temperatures (Williams 2003). An alternative to liquid chemicals for pre-wetting abrasives has been demonstrated in Norway and Ontario, Canada, is the use of very hot water. In this practice, material spreaders are equipped with water tanks that make it possible to heat water to $95^{\circ} \mathrm{C}$, and then the hot water is mixed with sand at the spreading disk (Vaa 2004; Perchanok et al. 2010; Wisconsin TIC 2005). After pre-wetting, the hot abrasives can melt a small quantity of snow or ice as the abrasives hit the road (Nixon 2001). Hot water sanding (HWS) technology can not only help prevent sand from being blown away from the road surface by traffic, but also reduce the quantity of road salt and winter sand needed. A test conducted in Norway showed that pre-wetting with hot water or heating abrasives maintained higher friction even after 2000 cars passed (Dahlen and Vaa 2001). As with most new practices, special equipment and operational and safety issues must be addressed when implementing new technology (Nixon 2009).

\subsection{Sanding}

Abrasives are applied to roadways to temporarily increase the friction coefficient, especially at low temperatures when chemical action is slow, and in conditions where strongly bonded snow and ice are difficult to remove. Generally, the increase in friction has a limited duration because traffic will rapidly disperse 
abrasives, particularly when traffic speeds are greater than $48 \mathrm{~km} / \mathrm{h}$ (Levelton Consultants 2007). In fact, abrasives, especially those not pre-wetted, have limited effectiveness on roads with higher vehicle speeds, and their use will not necessarily improve operations or mobility on many roads (CTC \& Associates LLC 2009). Additionally, research conducted by the Ontario Ministry of Transport showed that more salt-abrasives mixtures were required to achieve the same LOS as the straight use of salt (Conger 2005). In anti-icing operation, it was found that there were no significant advantages gained from the application of abrasives. The combined application of abrasives and chemicals in an anti-icing operation was no more effective in increasing the friction or improving the pavement condition than the same amount of chemicals alone, and it appears that the use of abrasives can be detrimental to the effectiveness of the chemical products (Ketcham et al. 1996). Additionally, abrasives have limitations, such as negative impacts on water quality and aquatic species, air quality, vegetation, and soil, as well as the cost of cleanup (Staples et al. 2004). Very fine sand particles are considered carcinogenic and contribute to air pollution and increased risk of lung diseases (Fischel 2001). Sand impacts water quality and threatens aquatic species habitats, particularly during spring runoff (Staples et al. 2004). Even after sweeping and vacuuming, $50 \%$ to $90 \%$ of sand remains somewhere in the environment (Parker 1997). Higher applications of abrasives, with few LOS benefits and more environmental impacts than chlorides, make them less desirable than salt (Salt Institute 2016).

\subsection{Plowing}

Under most conditions involving snow on the road, material application methodologies are an aid to snow plowing - deicers are not used to melt all the snow - they are applied to improve plowing. When plowing is employed at the appropriate timing and frequency, synergistic effects can be achieved between different methodologies, resulting in a cost-effective and environmentally sustainable solution. If snow and ice are removed by effective plowing practices before they bond to the pavement, the need for deicers decreases significantly.

The implementation of plowing can maximize snow removal from roadways and reduce costs such as operator and vehicle hours, fuel usage, and the amount of product used (TAC 2013). A case study in Otterburn Park, Quebec, reported a significant salt reduction of $73 \%$ through the implementation of effective plowing practices and improved training (Conger 2005). Most agencies establish plow routes based on factors such as traffic volume, emergency services, and local characteristics to improve snow removal efficiency. The timing of snow plowing operations is also critical to the overall effectiveness of snow removal. Depending on local policy, snow plowing operations are usually most successful when initiated after one to two inches of snow have fallen on the roadways. The highest level of service can be achieved if snow plowing operations begin before the snow is able to bond to the road surface, which is usually before heavy traffic occurs. After the storm event has concluded, a final clean-up plowing procedure is usually recommended with light salt application if necessary (NHDOT 2014). If deicing chemicals are applied, sufficient time is required for the melting action to occur before a snowplow can remove the compacted snow and ice. In addition, the more time a deicer remains on the roadway, the more traffic can assist in breaking the bond between the snow and the pavement (Wisconsin TIC 2005).

\section{Material application rates}

The application rate of WRM materials depends on a variety of factors, including application methodologies, air and pavement temperatures, amount of snow on the ground, and steepness of the roadway. There are two main tactics involving the application of chemicals, namely deicing and anti-icing, each of which may involve pre-wetted solids. Generally, deicing operation typically requires more chemicals (sometimes five times or more) than anti-icing operation (Levelton Consultants 2007). This is due to the significant loss of materials to the roadside environment by traffic action and the significant dilution effect of the snow lasting for hours or days, which are typically involved in the deicing operation. Pre-wetted salt works faster, at lower temperatures, and at reduced application rates, while pre-wetted abrasives tend to have less material loss from the pavement via bounce and scatter. In fact, pre-wetting can increase the material retention on the roadway by $26 \%$ (O'Keefe and Shi 2005).

Regardless of the treatment methodologies being selected, the optimal application rate always depends on the material type, pavement temperature, dilution potential, presence or absence of ice-pavement bond, plow circuit time, and LOS requirements. The surface temperature of a snow- or ice-covered road is particularly critical because it determines the snow melting capacity, dissolution, and penetration rates of the chemicals. As the temperature decreases, the amount of deicer needed to melt a given quantity of snow and ice increased significantly (Salt Institute 2016). The effectiveness of operations is sensitive to small differences in pavement temperature, and each chemical is effective only within a specific range of temperatures. For anti-icing, temperatures below $-7^{\circ} \mathrm{C}$, strong winds, and heavy snowfall or freezing rain conditions make anti-icing problematic or ineffective (Ketcham et al. 1996). It is best to apply anti-icing before snow events at temperatures higher than $-7^{\circ} \mathrm{C}$ (Blackburn et al. 2004; Peterson et al. 2010).

Survey results indicate that agencies also develop their own specifications and memoranda for material applications. Over the past 10 years, most agencies have developed new or revised guidelines. Commonly reported changes include increasing LOS for interstate and limited-access highways, shifting from abrasives to chemical priority, implementing guidelines for liquid and organic-based deicers, and including descriptive figures to illustrate abstract LOS. The suggested application rate ranges for the most common liquid products $\left(\mathrm{NaCl}, \mathrm{MgCl}_{2}\right.$, and $\mathrm{CaCl}_{2}$ ) and dry and pre-wet salt are shown in Tables $\mathrm{S} 2-\mathrm{S}^{1}$, which are available in the Supplementary data. These ranges are a synthesis of practices derived from the guidelines and experiences used by many state DOTs. Note that field experience has suggested that the application rates for DLA should be somewhat higher than those for anti-icing when using the same liquid product.

\section{Material application equipment}

Innovative equipment and technologies for road winter maintenance have developed significantly in recent years. In fact, many different vendors have invested significant resources in developing state-of-the-art controllers, spreading systems, road weather information systems (RWISs), hydraulic components, weather forecasting systems, and new-generation chemicals for snow and ice control operations. Relatively new maintenance practices such as fixed automated spray technology (FAST) systems, DLA, and slurry technology have been successfully explored as well. New on-truck tools (e.g., zero-velocity spreaders, modified spinners, and other delivery mechanisms) facilitate the precise and effective applications of both solid and liquid materials. Advanced systems use input from pavement surface condition sensors (friction, temperature, salinity, etc.) to adjust the amount of material being applied "on the fly," resulting in cost and environmental benefits. Several state DOTs have been developing a highway maintenance concept vehicle (HMCV) that incorporates some of the latest technologies, including temperature sensors, friction sensors, freeze point sensors, high-intensity lights, global positioning system (GPS)/automatic vehicle location (AVL), ground speed spreaders, pre-wetting equipment, liquid spreaders, power boosters, and underbody plows (Kroeger and Sinhaa 2004). Such technology seems to be most beneficial for high-volume roads that experience frequent road closures during 
winter weather (Cuelho and Kack 2002). This section provides a tabular overview of technology developments related to spreaders, liquid applicators, and systems related to the application of materials. Tables S6 and S7 ${ }^{1}$ in the Supplementary data show the configurations of solid material spreaders and liquid material applicators, respectively.

\section{Suggestions for further research}

A trend of shifting from solid chemicals to liquid chemicals was found in the survey results. When using salt brine, many different types of additives can be blended with it. The relationship between additive chemical composition, blending rate, and the resulting brine's effective temperature range and recommended field application rate is unclear for either anti-icing, deicing or prewetting. The storage and handling of these deicers should be better documented, such as mixing requirements, viscosity at different temperatures, chemical incompatibilities, and degradation during storage. Finally, the impact of the blended salt brine on the infrastructure (especially concrete and metals) should be studied.

For anti-icing, the timing of the operation can be a critical factor contributing to the effectiveness of its performance. However, there is no existing literature dedicated to providing scientific evidence on the relationship between the timing of anti-icing operation and the accuracy of road surface conditions. Research focusing on the timing of anti-icing should be conducted in the future.

Although the survey results show that most agencies are experiencing a shift from abrasives to chemical priority, many states still use abrasives. In their practice, salt is usually blended with abrasives to improve snow-melting performance. However, the amount of salt added varies from as low as $3 \%$ to as high as $50 \%$ by weight. The relationship between the salt additive rate and the abrasive particle size gradation remains unclear. The effect of the salt-added abrasives on the traction of roadways, particularly at temperatures below $-9{ }^{\circ} \mathrm{C}$, should be further investigated. Moreover, field investigations of freezing rain, blowing snow, and extremely cold conditions should be conducted to identify the best practices for these specific scenarios. Spreaders that can adjust application rates (and possibly material type) based on real-time sensor data (pavement temperature, friction, etc.) and location information (shade, hills, environment-sensitive areas, corrosion-sensitive structures) should be developed.

Finally, these responding agencies evaluated the cost-effectiveness and efficiency of different snow and ice control materials and application methodologies. Most agencies have conducted their own testing of materials, but more in the form of spot checking. However, the results of the evaluation vary from agency to agency. It is necessary to conduct well-designed field trials and in-depth testing of chemicals.

\section{Concluding remarks}

To update material application guidelines and synthesize the relevant best practices, this review highlights current practices, innovative practices, trends related to materials used, their application rates, application methodologies, and equipment used in winter roadway maintenance. The reviewed materials mainly focus on the products commonly used by highway agencies during their anti-icing, deicing, sanding, and pre-wetting operations, including solid salts, chloride brines, and non-chloride liquids applied directly or as additives to abrasives and chemicals. By reviewing the related literature from the past decade or two and the survey results from agencies in cold climates, the new knowledge obtained can be summarized as follows.

- LOS has the highest priority over any other factor that influences the choice of material, methodology, and equipment of the material application.
- Abrasives are still in use in many locations, especially during extremely cold temperatures and on low-volume, low-LOS routes. Salt, in solid or liquid form, is the most commonly used chemical during winter events.

- The renewed application rate for both solid and liquid materials can provide guidelines for highway agencies as a starting point.

- Agencies have explored the use of liquid materials for deicing, called direct liquid application, where only liquid materials are used during and after a storm.

- Equipment incorporated with new methods and technology developments is now available for use in winter road maintenance operations, which can apply materials automatically and more precisely.

\section{Acknowledgements}

The authors acknowledge the funding provided by the Minnesota Department of Transportation. We would also like to thank all the states and agencies for their cooperation and sharing their experiences during the interviews, and for providing agency guidelines, documents, and photographs. Xianming Shi also acknowledges the Tier 1 University Transportation Center CAMMSE (Center for Advanced Multi-modal Mobility Solutions and Education) for funding his time in preparing this manuscript.

\section{References}

Alger, R., and Haase, J. 2006. Analysis of the benefits of bulk pre-wetting solid $\mathrm{NaCl}$ with several different liquids. Research Report RC-1473. Michigan Department of Transportation, Lansing, Mich.

BC Ministry of Transportation \& Infrastructure. 2001. Snowplows, sand and gravel trucks: Tranportation Topic No. 3. British Columbia Ministry of Transportation \& Infrastructure. Available from http://www.th.gov.bc.ca/populartopics/documents/Fact_Sheets/tt3.pdf.

Bell, G.T., Nixon, W.A., and Stowe, R.D. 2006. A synthesis to improve the design and construction of Colorado's bridge anti-icing systems. Final report CDOT-DTD-R-2005-19. Colorado Department of Transportation, Denver, Colo.

Blackburn \& Associates. 2014. Establishing effective salt and anti-icing application rates. Summary Report Task 2: update guidelines. Clear Roads.

Blackburn, R.R., Bauer, K.M., Amsler, D.E., Boselly, S.E., and Mcelroy, A.D. 2004. Snow and ice control: guidelines for materials and methods. NCHRP Report 526. Transportation Research Board, Washington, DC.

Boselly, S.E. 2008. Update of the AASHTO guide for snow and ice control. American Association of State Highway and Transportation Officials (AASHTO), Washington, DC.

Burtwell, M. 2004. Deicing trails on UK Roads: performance of prewetted salt spreading and dry salt spreading. In Proceedings of the 6th International Symposium on Snow Removal and Ice Control Technology, Spokane, Wash., 7-9 June, 2004

City of Brockville. 2018. Salt management plan. Available: http://brockville. com/UploadedFiles/Salt\%20Management\%20Plan\%20Revised\%202018.pdf.

Conger, S.M. 2005. Winter highway operations: a synthesis of highway practice. NCHRP Synthesis 344. Transportation Research Board, Washington, DC.

CTC \& Associates LLC. 2009. Anti-icing in Winter Maintenance Operations: Examination of Research and Survey of State Practice. TRS 0902. Minnesota Department of Transportation, St. Paul, Minn.

Cuelho, E., and Kack, D. 2002. Needs assessment and cost/benefit analysis of the roadview advanced snowplow technology system. Final Report FHWA/CA/ NT-2002/08-A. California Department of Transportation, Sacramento, Calif.

Cuelho, E., Harwood, J., Akin, M., and Adams, E. 2010. Establishing best practices for removing snow and ice from California roadways. Final Report CA101101. Department of Research and Innovation California Department of Transportation.

Cui, N., and Shi, X. 2015. Improved user experience and scientific understanding of anti-icing and pre-wetting for winter maintenance in North America. In Proceedings of the International Symposium on Systematic Approaches to Environmental Sustainability in Transportation, Fairbanks, Alaska, 2-5 August, 2015. American Society of Civil Engineers, Reston, Va. doi:10.1061/9780784479285.010.

Dahlen, J., and Vaa, T. 2001. Winter friction project in Norway. Transportation Research Record: Journal of the Transportation Research Board, 1741: 34-41. doi:10.3141/1741-06.

Dindorf, C., and Fortin, C. 2014. The real cost of salt use for winter maintenance in the Twin Cities Metropolitan Area. Minnesota Pollution Control Agency.

Dye, D.L., Krug, H.O., Keep, D., and Willard, R. 1996. Experiments with anti-icing in Washington State. Transportation Research Record: Journal of the Transportation Research Board, 1533: 21-26. doi:10.1177/0361198196153300103. 
Environment Canada. 2002. Risk management strategy for road salts. Environment Canada, Regulatory \& Economic Analysis Branch.

Evans, M.D. 2008. Winter Maintenance Manual. Utah LTAP Center, Utah State University, Logan, UT.

Fay, L., and Shi, X. 2011. Laboratory investigation of performance and impacts of snow and ice control chemicals for winter road service. Journal of Cold Regions Engineering, ASCE, 25(3): 89-114. doi:10.1061/(ASCE) CR.1943-5495.0000025.

Fay, L., and Shi, X. 2012. Environmental impacts of chemicals for snow and ice control: state of the knowledge. Water, Air, \& Soil Pollution, 223(5): 2751-2770. doi:10.1007/s11270-011-1064-6.

Fay, L., Shi, X., Venner, M., and Strecker, E. 2014. Toxicological effects of chloride-based deicers in the natural environment. NCHRP Project 25-25. American Association of State Highway and Transportation Officials, Washington, DC

FHWA. 2013. Snow and ice. Federal Highway Administration, Washington, DC. Available from https://ops.fhwa.dot.gov/weather/weather_events/snow_ice.htm.

Fischel, M. 2001. Evaluation of selected deicers based on a review of the literature. Final Report CDOT-DTD-R-2001-15. Colorado Department of Transportation, Denver, Colo.

Fortin Consulting. 2017. The future of winter maintenance involves liquid only strategies. Dane County Department of Land and Water Resource, Madison, Wisc

Fu, L., Sooklall, R., and Perchanok, M. 2006. Effectiveness of alternative chemicals for snow removal on highways. Transportation Research Record: Journal of the Transportation Research Board, 1948: 125-134. doi:10.1177| 0361198106194800114

Gerbino-Bevins, B.M. 2011. Performance rating of de-icing chemicals for winter operations. Master's thesis, University of Nebraska, Lincoln, NE.

Goodwin, L.C. 2003. Best practices for road weather management, Version 2.0. FHWA-OP-03-081. Federal Highway Administration, Washington, DC.

Hossain, S.M.K., Fu, L., Hosseini, F., Muresan, M., Donnelly, T., and Kabir, S. 2016. Optimum winter road maintenance: effect of pavement types on snow melting performance of road salts. Canadian Journal of Civil Engineering, 43(9): 802-811. doi:10.1139/cjce-2016-0010.

Hosseini, F., Hossain, S.K., Fu, L., San Gabriel, P., and Van Seters, T. 2014 Field evaluation of organic materials for winter snow and ice control. In Proceedings of the 9th Annual Transportation Research Board.

Johnson, A.M. 2000. Establishment, protection, and reestablishment of urban roadside vegetation against salt and ice. Final Report No. MN/RC-2000-33. Minnesota Department of Transportation, Saint Paul, Minn.

Kahl, S. 2002. Agricultural by-products for anti-icing and deicing use in Michigan. Research Report R1418. Michigan Department of Transportation, Lansing, Mich.

Keep, D., and Parker, D. 2000. Proactive guide to snow and ice control: a guide for highway winter maintenance personnel. Ice and Snow Technologies, LLC, Walla Walla, Wash.

Ketcham, S.A., Minsk, L.D., Blackburn, R.R., and Fleege, E.J. 1996. Manual of practice for an effective anti-icing program: a guide for highway winter maintenance personnel. Federal Highway Administration, Washington, DC.

Kroeger, D.A., and Sinhaa, R. 2004. A business case for winter maintenance technology applications: highway maintenance concept vehicle. In Proceedings of the 6th International Symposium on Snow Removal and Ice Control Technology, Doubletree Spokane City Center, Spokane, Wash., 7-9 June, 2004. Transportation Research E-Circular E-C063.

Levelton Consultants. 2007. Guidelines for the selection of snow and ice control materials to mitigate environmental impacts. NCHRP Report 577. Transportation Research Board, Washington, DC.

Li, Y., Fang, Y., Seeley, N., Jungwirth, S., Jackson, E., and Shi, X. 2013. Corrosion by chloride deicers on highway maintenance equipment: renewed perspective and laboratory investigation. Transportation Research Record, Journal of the Transportation Research Board, 2361: 106-113. doi:10.3141/2361-13.

Lokal Profil. 2020. File:map of US state cannabis laws. Available from https:/ commons.wikimedia.org/wiki/File:Map_of_US_state_cannabis_laws.svg.

Maine DOT. 2003. Comparison tests of liquid calcium and salt brine: a controlled experimental evaluation of rock salt pre-wetting liquids. Research Report 0303. Maine Department of Transportation (Maine DOT), Augusta, Maine.

Matthews, L., Andrey, J., and Picketts, I. 2017. Planning for winter road maintenance in the context of climate change. Weather, Climate, and Society, 9(3): 521-532. doi:10.1175/WCAS-D-16-0103.1.

MDOT Strom Water Management Team \& Tetra Tech. 2006. Emerging technologies in winter road maintenance: improving safety while minimizing environmental impacts. Michigan Department of Transportation, Lansing, Mich.

Mitchell, G., Hunt, C., and Richardson, W. 2003. Evaluation of ODOT roadway/weather sensor systems for snow and ice removal operations Part III, optimization of salt brine pre-treatment application rates and frequency. Final Report FHWA/OH-2003/008C. Ohio Department of Transportation, Columbus, $\mathrm{OH}$

Mitchell, G.F., Richardson, W., and Russ, A. 2006. Evaluation of ODOT roadway/weather sensor systems for snow and ice removal operations/RWIS Part IV: optimization of pretreatment or anti-icing protocol. Technical Report FHWA/OH-2006/24. Ohio Department of Transportation, Columbus, OH.

Minnesota Pollution Control Agency. 2016. Lowest practical melting temperature. Minnesota stormwater manual. Minnesota Pollution Control Agency.
Available from https://stormwater.pca.state.mn.us/index.php?title=Lowest_ practical_melting_temperature.

MnDOT. 2010. Mn/DOT anti-icing guide. Minnesota Department of Transportation (MnDOT), St. Paul, Minn. Available from https://www.dot.state.mn. us/maintenance/pdf/research/AntiIcingGuide8Full.pdf.

Muthumani, A., Fay, L., and Shi, X. 2017. Agricultural by-products weaken the snow/ice bond to pavement and improve sunlight absorbance and longevity on road. In Proceedings of the Transportation Research Board 96th Annual Meeting, Washington, DC, 8-12 January, 2017.

Nazari, M.H., and Shi, X. 2019. Developing renewable agro-based anti-icers for sustainable winter road maintenance operations. Journal of Materials in Civil Engineering, ASCE, 31(12): 04019299. doi:10.1061/(ASCE)MT.1943-5533.0002963.

Nazari, M.H., Shi, X., Jackson, E., Zhang, Y., and Li, Y. 2017. Laboratory investigation of washing practices and bio-based additive for mitigating metallic corrosion by magnesium chloride deicer. Journal of Materials in Civil Engineering, ASCE, 29(1): 04016187. doi:10.1061/(ASCE)MT.1943-5533.0001727.

Nazari, M.H., Mousavi, S.Z., Potapova, A., McIntyre, J., and Shi, X. 2021. Toxicological Impacts of Roadway Deicers on Aquatic Resources and Human Health: A Review, 93: 1855-1881.

NH DoES. 2016. Road salt and water quality. Environmental Fact Sheet WD-WMB4. New Hampshire Department of Environmental Services, Concord, NH. Available: https://www.des.nh.gov/sites/g/files/ehbemt341/files/documents/wmb-4.pdf.

NHDOT. 2014. Winter maintenance snow removal and ice control policy. New Hampshire Department of Transportation (NHDOT), Concord, NH

Nixon, W.A. 2001. The use of abrasives in winter maintenance final report of Project TR 434. Technical Report No. 416. Iowa Department of Transportation \& The Iowa Highway Research Board.

Nixon, W.A. 2008. Economics of Using Calcium Chloride vs. Sodium Chloride for Deicing/Anti-Icing. Final Report TR488. Iowa Highway Research Board.

Nixon, W.A. 2009. Field testing of abrasive delivery systems in winter maintenance. Technical Report \#471. Iowa Highway Research Board.

Nixon, W.A., and Williams, A.D. 2001. A guide for selecting anti-icing chemicals, Version 1.0. Technical Report No. 420. IIHR-Hydroscience and Engineering, University of Iowa, Iowa City, IA

Norem, H. 2009. Selection of strategies for winter maintenance of roads based on climatic parameters. Journal of Cold Regions Engineering, ASCE, 23(4): 113-135. doi:10.1061/(ASCE)0887-381X(2009)23:4(113).

Novotny, E.V., Murphy, D., and Stefan, H.G. 2008. Increase of urban lake salinity by road deicing salt. The Science of the Total Environment, 406(1-2): 131-144. doi:10.1016/j.scitotenv.2008.07.037.

O'Keefe, K., and Shi, X. 2005. Synthesis of information on anti-icing and pre-wetting for winter highway maintenance practices in North America. Final Report. Pacific Northwest Snowfighters Association \& Washington State Department of Transportation.

Parker, D. 1997. Alternative snow and ice control methods: field evaluation. Field Evaluation No. FHWA-OR-RD-98-03. Oregon Department of Transportation, Salem, Ore.

Perchanok, M., Fu, L., Feng, F., Usman, T., McClintock, H., Young, J., and Fleming, K. 2010. Sustainable winter sanding with pre-wetting. In Proceedings of Managing the Risk of Aging Infrastructure in the Face of Climate Change and Reduced Operating Budgets Session of the 2010 Annual Conference of the Transportation Association of Canada, Halifax, NS. 13 pp.

Peterson, G., Keranen, P., and Pletan, R. 2010. Identifying the parameter for effective implementation of liquid-only plow routes. Clear Roads 09-02. Wisconsin Department of Transportation.

Qiao, C., Hosseinzadeh, N., Suraneni, P., Wei, S., and Rothstein, D. 2021. Petrographically quantifying the damage to field and lab-cast mortars subject to freeze-thaw cycles and deicer application. Journal of Infrastructure Preservation and Resilience, 2: 9.

Radaelli, M., and Dizaji, R. 2017. Combined analysis of pre-treated salt trials. Final Report 5014-M-0033. Ministry of Transportation Ontario, Toronto, Ont.

Rainwater, K.A., Lawson, W.D., Surles, J.G., Estrada, F.J., and Jackson, W.A. 2021. Side-by-side field comparison of snow and ice control chemicals for anti-icing applications. Cold Regions Science and Technology, 184: 103230.

Resource Concepts Inc. 1992. Survey of: alternative road deicers technical report. FHWA-SA95-040. Nevada Department of Transportation of Transportation and California Department of Transportation.

Roosevelt, D.S. 2004. A bridge deck anti-icing system in Virginia: lessons learned from a pilot study. Final Report VTRC 04-R26. Virginia Transportation Research Council \& U.S. Department of Transportation Federal Highway Administration.

Rubin, J., Garder, P.E., Morris, C.E., Nichols, K.L., Peckenham, J.M., McKee, P., Stern, A., and Johnson, T.O. 2010. Maine winter roads: salt, safety, environment and cost: executive summary. Maine Department of Transportation, Augusta, ME.

Sajid, H.U., Kiran, R., Qi, X., Bajwa, D.S., and Battocchi, D. 2020. Employing corn derived products to reduce the corrosivity of pavement deicing materials. Construction and Building Materials, 263: 120662.

Salt Institute. 2003. Effective temperature of deicing chemicals. Snow \& Ice Fact \#20, FY03.

Salt Institute. 2016. The snowfighter's handbook. Available from http://saltinstitute. org/wp-content/uploads/2015/02/SASS-Handbook-2016-1.pdf.

Schweigert, N. 2016. Characterization of runway deicers. Study report. French Civil Aviation Authority. 
Shi, X. 2020. More than smart pavements: connected infrastructure paves the way for enhanced winter safety and mobility on highways. Journal of Infrastructure Preservation and Resilience, 1(1): 13.

Shi, X., Akin, M., Pan, T., Fay, L., Liu, Y., and Yang, Z. 2009a. Deicer impacts on pavement materials: introduction and recent developments. The Open Civil Engineering Journal, 3(1): 16-27. doi:10.2174/1874149500903010016.

Shi, X., Fay, L., Gallaway, C., Volkening, K., Peterson, M.M., Pan, T., et al. 2009b. Evaluation of alternative anti-icing and deicing compounds using sodium chloride and magnesium chloride as baseline deicers - Phase I. Final Report No. CDOT-2009-1. Colorado Department of Transportation, Denver, Colo.

Shi, X., Liu, Y., Mooney, M., Berry, M., Hubbard, B., and Nguyen, T.A. 2010. Laboratory investigation and neural networks modeling of deicer ingress into Portland cement concrete and its corrosion implications. Corrosion Reviews, 28 (3-4): 105-154.

Stantec Consulting. 2012. Winter sanding guidelines. Saskatchewan Municipalities.

Staples, J.M., Gamradt, L., Stein, O., and Shi, X. 2004. Recommendations for winter traction materials management on roadways adjacent to bodies of water. Final Report No. FHWA/MT-04-008/8117-19. Montana Department of Transportation, Helena, MT.

Sutter, L., Peterson, K., Julio-Betancourt, G., Hooton, D., Dam, T.V., and Smith, K. 2008. The deleterious chemical effects of concentrated deicing solutions on Portland cement concrete. Final Report SD2002-01-F. South Dakota Department of Transportation, Pierre, SD.

TAC. 2013. Syntheses of Best Practices Road Salt Management: 9.0 - Winter Maintenance Equipment and Technologies. Transportation Association of Canada (TAC), Ottawa, Ont.

Thompson, G., and Thompson, T. 2014. Clear roads: developing a totally automated spreading system. Final Report TEC-006-14. Minnesota Department of Transportation, St. Paul, Minn.

TRB. 1991. Highway deicing: comparing salt and calcium magnesium acetate. Special Report 235. Transportation Research Board Committee on the Comparative Costs of Rock Salt and Calcium Magnesium Acetate (CMA) for Highway Deicing, Washington, DC.

Trenouth, W.R., Gharabaghi, B., and Perera, N. 2015. Road salt application planning tool for winter de-icing operations. Journal of Hydrology, 524: 401-410. doi:10.1016/j.jhydrol.2015.03.004.

Vaa, T. 2004. Implementation of new sanding method in Norway. In Proceedings of the 6th International Symposium on Snow Removal and Ice Control Technology, Spokane, Wash., 7-9 June, 2004.
Veneziano, D., Zhirui, Y., and Turnbull, I. 2014. Speed impacts of an icy curve warning system. IET Intelligent Transport Systems, 8: 93-101. doi:10. 1049/iet-its.2012.0110.

Venner Consulting and Parsons Brinckerhof. 2004. Environmental stewardship practices, procedures, and policies for highway construction and maintenance. American Association of State Highway and Transportation Officials.

Waldman, J.R. 2004. State-of-the-art fixed automated spray technology. In Proceedings of the 6th International Symposium on Snow Removal and Ice Control Technology, Spokane, Wash., 7-9 June, 2004.

Wegner, W., and Yaggi, M. 2001. Environmental impacts of road salt and alternatives in the New York City watershed. Stormwater, 2(5): 24-31.

Williams, D. 2003. Past and current practices of winter maintenance at the Montana Department of Transportation (MDT). Montana Department of Transportation, Helena, MT.

Wisconsin TIC. 2005. Pre-wetting and anti-icing - techniques for winter road maintenance. Wisconsin Transportation Bulletin, No. 22, 8 pp.

$\mathrm{Xi}$, Y., and Oisgard, P.J. 2000. Effects of de-icing agent (magnesium chloride and sodium chloride) on corrosion of truck Components. Final Report No. CDOT-DTD-R-2000-10. Colorado Department of Transportation, Denver, Colo.

Xie, N., Shi, X., and Zhang, Y. 2016. Impacts of potassium acetate and sodiumchloride deicers on concrete. Journal of Materials in Civil Engineering, ASCE, 29(3): 04016229. doi:10.1061/(ASCE)MT.1943-5533.0001754.

Xie, N., Dang, Y., and Shi, X. 2019. New insights into how $\mathrm{MgCl} 2$ deteriorates Portland cement concrete. Cement and Concrete Research, 120: 244-255.

Xu, G., Sturges, L., Chapman, M., Albrecht, C., Bergner, D., and Shi, X. 2017. Snow removal performance metrics: past, present, and future. Transportation Research Record, 2613(1): 61-70.

Zhang, J., Das, D., Peterson, R., and Goering, D. 2007. Comprehensive evaluation of bridge anti-icing technologie. Final Report No. INE/AUTC 07.06. Alaska Department of Transportation and Public Facilities, Juneau, AK.

Zhang, Y., Akin, M., and Shi, X. 2020. Laboratory Investigation of Prewet Deicer Performance for Winter Mobility in the Pacific Northwest. Journal of Cold Regions Engineering, 34(4): 04020022.

Zhang, Y., Sun, T., Li, F., Wang, J., and Oh, K. 2013. Effect of decing salts on ion concentrations in Urban stormwater runoff. Procedia Environmental Sciences, 18: 567-571. doi:10.1016/j.proenv.2013.04.076. 